\title{
Potential drug interactions with cholinesterase inhibitors in Alzheimer patients: A guideline for Neurologists
}

\author{
Maryam Mehrpouya $^{1}$, Sara Ataei $^{1^{*}}$, Amir Nili-Ahmadabadi ${ }^{2}$ \\ ${ }^{1}$ Department of Clinical Pharmacy, School of Pharmacy, Hamadan University of Medical Sciences, Hamadan, Iran. \\ ${ }^{2}$ Department of Pharmacology and Toxicology, School of Pharmacy, Hamadan University of Medical Sciences, Hamadan, Iran.
}

\section{ARTICLE INFO \\ Article history: \\ Received on: $27 / 04 / 2016$ \\ Revised on: 28/05/2016 \\ Accepted on: 14/06/2016 \\ Available online: 31/01/2017}

Key words:

Cholinesterase inhibitors,

drug interaction, Alzheimer's

disease, polypharmacy.

\begin{abstract}
Cholinesterase inhibitors are used for the symptomatic treatment of patients with Alzheimer's disease (AD). This population often has numerous comorbidities and is treated with multiple medications, which leads to polypharmacy. Possible pharmacokinetic and pharmacodynamic drug interactions may occur with this type of concomitant treatment, such as interactions with antipsychotics, antidepressants, anticholinergics, and cardiovascular and urinary disorder medications. Drug interactions should always be considered to reduce the risk of side effects and other problems for patients and also to increase the effectiveness of therapeutic drugs for AD.
\end{abstract}

\section{INTRODUCTION}

Cholinesterase is a family of enzymes that catalyzes the hydrolysis of the neurotransmitter acetylcholine into choline and acetic acid, a reaction necessary to allow a cholinergic neuron to return to its resting state after activation. These enzymes break down acetylcholine in the brain; if their action is inhibited, more acetylcholine is available for communication between brain cells (Colovic et al., 2013). Patients with Alzheimer disease (AD) have reduced cerebral production of choline acetyl transferase, which leads to a decrease in acetylcholine synthesis and impaired cortical cholinergic function, therefore Cholinesterase inhibitors (ChEIs) were the first medication approved by the Food and Drug Administration (FDA) for the treatment of cognitive deficits in AD (Lopez et al., 2002). Commonly prescribed medications, such as antihistamines and tricyclic antidepressants

\footnotetext{
* Corresponding Author

Dr. Sara Ataei, Department of Clinical Pharmacy, Faculty of Pharmacy, Hamadan University of Medical Sciences, Hamadan, Iran. Tel/Fax:+988138380031; Email: s.ataei @ umsha.ac.ir
}

(TCAs), often have anticholinergic properties that alone or in combination with other medications can antagonize the effects of CEIs. Other medication classes, such as antipsychotics and cholinergic agents, may also result in pharmacodynamic interactions (Tavassoli et al., 2007). One of the crucial consequences of an aging population (older than 65 years of age) is the higher prevalence of age-related disorders. Hence, the negative impact of polypharmacy, the use of multiple medications, generally ranges from 5 to 10 , by a patient, is an inevitable phenomenon of this change in the health condition of the elderly in general and in AD patients specifically (Campanelli, 2012; Fick et al., 2003; Linjakumpu et al., 2002).

Considering the importance of drug interactions in these frail patients, professionals who work in geriatric field should pay more attention to this issue, especially in developing countries that have health systems with limited resources (Narayan et al., 2013; Roe et al., 2002). The aim of this mini review was to provide a practical study about important drug interactions with $\mathrm{AD}$ medications, such as ChEIs, for professionals who work in the field of dementia. 


\section{Method}

The PubMed and Elsevier databases were searched for surveys published during the last five years. Other applicable resources, such as the UpToDate subscription-based resource database, Lexicomp (a clinical drug information database), and the American Geriatric Society Updated Beers Criteria, were used. The interaction between ChEIs and Memantine with current medications prescribed for the treatment of common chronic disorders in elderly patients with AD have been studied. We selected medications that are approved for use in elderly patients with AD. Therefore, any medications that are contraindicated or should be avoided (like clidinium- $\mathrm{C}$ and cimetidine) have not been included in this review.

\section{Results}

The AD population often has many comorbidities and receives treatment with multiple medications. The astute clinician should remain mindful of possible drug interactions (both pharmacokinetic and pharmacodynamic) that may occur with concomitant treatment.

We have listed the drug interactions between ChEIs and Memantine with medications used for common chronic disorders in $\mathrm{AD}$ patients along with their pharmaceutical applications, such as UpToDate, Lexicomp, and a few books in the field of drug-drug interactions, such as Drug Interaction Facts.

Tables 1-4 have also been included to show possible interactions in these diverse classes of medications. As shown in table 5, some of these interactions have been reported so important that patients who use these medications should be advised to consider therapy modification to prevent deleterious effects. Other drug combinations should be avoided, while still others carry the recommendation for closely monitoring the patient's therapy.

Table 1: Drug interactions between AChE-Is and Memantine with antidepressants.

\begin{tabular}{ccccc}
\hline Interactions & Rivastigmine & Donepezil & Galantamine & Memantine \\
\hline TCAs & Tertiary TCAs decrease pharmacologic effects of AChEIs; Exception: Desipramine and Nortriptyline with caution & No interaction \\
\hline SSRIs & $\begin{array}{c}\text { Paroxetine should be } \\
\text { avoided, }\end{array}$ & $\begin{array}{c}\text { Paroxetine should be avoided, } \\
\text { its anticholinergic effect may } \\
\text { its anticholinergic effect } \\
\text { may diminish efficacy of } \\
\text { Rivastigmine. }\end{array}$ & $\begin{array}{c}\text { Fluvoxamine, Fluoxetine and Paroxetine should be } \\
\text { avoided, Fluoxetine and Fluvoxamine can increase } \\
\text { galantamine plasma concentration; anticholinergic } \\
\text { effect of paroxetine may diminish } \\
\text { efficacy of donepezil }\end{array}$ & $\begin{array}{c}\text { No interaction } \\
\end{array}$ \\
\hline Bupropion & & Increase risk of seizure & Reduce renal clearance
\end{tabular}

Bupropion

Increase risk of seizure of memantine

Online drug information database, Lexi-Interact ${ }^{\mathrm{TM}}$ Online

Table 2: Drug interactions between AChE-Is and Memantine with urinary anticholinergics.

\begin{tabular}{cccc}
\hline Interactions & Rivastigmine & Donepezil & Malantamine \\
\hline Propantheline & Urinary anticholinergic agents may antagonize therapeutic efficacy of acetylcholinesterase inhibitors. & No interaction \\
Oxybutynin & Solifenacin and Darifenacin has the least interaction and is drug of choice in these patients. & No interaction & No interaction \\
Tolterodine & & & \\
Solifenacin & & & \\
\hline
\end{tabular}

Online drug information database, Lexi-Interact ${ }^{\mathrm{TM}}$ Online

Table 3: Drug interactions between AChE-Is and Memantine with antipsychotics.

\begin{tabular}{ccc}
\hline Interactions & Rivastigmine & Galantamine \\
\hline Quetiapine & Donepezil & No interaction \\
Olanzapine & & No interaction \\
Risperidone & & No interaction \\
Aripiprazole & & No interaction \\
Clozapine & Anticholinergic effects of these medications can diminish therapeutic effects of Acetylcholinesterase & No interaction \\
Haloperidol & inhibitors. Increase risk of QT interval prolongation and torsade de pointes. & No interaction \\
Trifluoperazine & & No interaction \\
Chlorpromazine & & No interaction \\
Ziprasidone & & No interaction \\
\hline
\end{tabular}

Online drug information database, Lexi-Interact ${ }^{\mathrm{TM}}$ Online

Table 4: Drug interactions between AChE-Is and Memantine with cardiovascular drugs.

\begin{tabular}{|c|c|c|c|}
\hline Interactions & Examples & Galantamine & Memantine \\
\hline Beta Blockers & Atenolol, Carvedilol, Metoprolol,Sotalol & Vagotonic effects of AchEIs on SA and AV nodes with & No interaction \\
\hline Non-Dihydropyridine CCBs & Diltiazem Verapamil & concomitant use of these medications can cause & No interaction \\
\hline Digitalis Preparation & Digoxin & bradycardia and heart block. The most vagotonic & No interaction \\
\hline Antiarrhythmic Agents & $\begin{array}{c}\text { Disopyramide, Procainamide, Quinidine, } \\
\text { Amiodarone }\end{array}$ & $\begin{array}{l}\text { effect has seen with rivastigmine and the least effect has } \\
\text { seen with galantamine. Monitor patient regularly. }\end{array}$ & No interaction \\
\hline Diuretics & $\begin{array}{c}\text { HCTZ } \\
\text { Furosemide }\end{array}$ & No interaction & $\begin{array}{l}\text { Altered plasma levels } \\
\text { of memantine and } \\
\text { HCTZ, not clinically } \\
\text { important }\end{array}$ \\
\hline
\end{tabular}


Table 5: Examples of some potential drug-drug interactions in Alzheimer's patients taking cognitive enhancers.

\begin{tabular}{|c|c|c|c|c|}
\hline Interaction & Mechanism & $\begin{array}{c}\text { Results Articles } \\
\end{array}$ & Description & Ref \\
\hline \multirow[b]{2}{*}{$\begin{array}{c}\text { AChEIs + } \\
\text { anticholinergics }\end{array}$} & \multirow[b]{2}{*}{$\begin{array}{l}\downarrow \text { Acetylcholine in } \\
\text { CNS }\end{array}$} & $\begin{array}{l}\text { Anticholinergic drugs may antagonize } \\
\text { the effects of cholinesterase inhibitors. }\end{array}$ & This drug combination should be avoided. & $\begin{array}{c}\text { (Johnell and } \\
\text { Fastbom, 2008). }\end{array}$ \\
\hline & & $\begin{array}{l}\text { dual use of ChEIs and bladder } \\
\text { anticholinergics may result in decline } \\
\text { activity of daily living function. }\end{array}$ & $\begin{array}{l}\text { bladder anticholinergics such as oxybutynin or } \\
\text { tolterodine with ChEIs } \\
\text { may result in greater rates of functional decline } \\
\text { than use of ChEIs alone. }\end{array}$ & (Sink et al., 2008) \\
\hline $\begin{array}{l}\text { AChEIs + Beta } \\
\text { Blockers }\end{array}$ & $\begin{array}{l}\text { Vagal Stimulation } \\
\text { and Sympathetic } \\
\text { blockade }\end{array}$ & $\begin{array}{l}\text { Concurrent use of AChEIs and beta } \\
\text { blockers could worsen bradycardia and } \\
\text { cause syncope. }\end{array}$ & $\begin{array}{l}\text { In patients taking these cardiovascular drugs, make } \\
\text { sure that heart rate is }>60 \mathrm{bpm} \text { before AChEI } \\
\text { treatment, and monitor regularly. }\end{array}$ & $\begin{array}{l}\text { (Paulison and } \\
\text { Léos, 2010) }\end{array}$ \\
\hline $\begin{array}{c}\text { AChEIs + } \\
\text { Antipsychotics }\end{array}$ & $\begin{array}{l}\text { This interaction } \\
\text { produces an } \\
\text { extrapyramidal } \\
\text { syndrome and } \\
\text { worsening of } \\
\text { extrapyramidal } \\
\text { adverse effects }\end{array}$ & $\begin{array}{l}\text { This interaction may be attributable to a } \\
\text { relative imbalance of cholinergic and } \\
\text { dopaminergic activity in the striatum, } \\
\text { which may occur following } \\
\text { concomitant administration of a } \\
\text { dopaminolytic and a cholinesterase } \\
\text { inhibitor. }\end{array}$ & $\begin{array}{l}\text { For example,Donepezil significantly potentiated } \\
\text { bradykinesia induction with a low dose of } \\
\text { haloperidol and worsening of extrapyramidal } \\
\text { adverse effects in patients receiving a combination } \\
\text { of donepezil and risperidone. }\end{array}$ & $\begin{array}{l}\text { (Shimizu et al., } \\
\text { 2015) } \\
\text { (Magnuson } \text { et al., } \\
\text { 1998) } \\
\text { (Liu et al., 2002) } \\
\text { (Pasqualetti et al., } \\
\text { 2015) }\end{array}$ \\
\hline
\end{tabular}

\section{DISCUSSION}

The neuropsychiatric symptoms in $\mathrm{AD}$ and other types of dementia are extremely common and often much more troubling than amnestic symptoms. Depression is also a frequent psychiatric disorder in this group of patients (Lyketsos and Lee, 2003), and drugs to treat this and other symptoms are often prescribed to $\mathrm{AD}$ patients. For example, selective serotonin reuptake inhibitors (SSRIs) are useful in the management of agitation and paranoia in the AD population (Seitz et al., 2011).

The selection of a specific SSRI is generally based upon its side effect profile, any drug interactions, and cost. Fluvoxamine, fluoxetine, and paroxetine are not good choices due to drug interactions that result from their inhibition of CYP $2 \mathrm{C}$, which reduces the metabolism of some drugs prescribed concomitantly; paroxetine in particular has significant anticholinergic effects (Preskorn, 1997).

Among the drugs in this category, citalopram and scitalopram are the most suitable choice for these patients because they produce fewer drug interactions; however, due to the increased risk of cardiac arrhythmia in patients using citalopram (especially in the elderly at higher doses), any dose higher than 20 $\mathrm{mg}$ daily is not recommended in these patients (Porsteinsson et al., 2014). The anticholinergic properties of TCAs can increase confusion and reduce the positive effects of the ChEIs (Table 1); therefore, nortriptyline should be considered due to its lower incidence of adverse anticholinergic effects compared to other TCAs, as it is typically a better tolerated choice (Taragano et al., 1997). Sleep disturbances are also common in patients with AD. Drugs prescribed to treat these disturbances may also interact with other drugs that elderly patients are taking. Usually, for overcome of sleep disorders, medications such as antipsychotic and/or antidepressant drugs are prescribed by physician for $\mathrm{AD}$ patients. Therefore, the interaction between these drugs with the class of ChEIs should be kept in mind (Katz et al., 1998).

Antipsychotics are often used in concomitant with ChEIs to treat the behavioral and psychological symptoms of dementia. The practitioners should take in consideration the interactions between ChEIs and antipsychotic drugs. It is important to consider the interactions between ChEIs and antipsychotic drugs to obtain the most effective treatment for patients with $\mathrm{AD}$. It is thought that the co-prescription of ChEIs and dopamine D2 receptor blockers may induce an acetylcholine/dopamine imbalance in the striatum, producing an extrapyramidal syndrome and making extrapyramidal adverse effects worse (Table 3). Agitation and aggression are frequently occurring and distressing behavioral and psychological symptoms of dementia. The most widely prescribed pharmacological treatments for these symptoms are atypical antipsychotics (Ballard et al., 2009).

\section{CONCLUSION}

An interdisciplinary "geriatric assessment" is essential for a comprehensive evaluation of the prescriptions in the patients with $\mathrm{AD}$ who receive ChEIs and Memantine. Moreover raising awareness of the professionals and families about careful drug regimen review is essential to identify potentially inappropriate or hazardous medications to modify the treatment protocol (Tanaka $e t$ al., 2009). This assessment might reduce the length of hospital admissions, related costs and patient mortality and morbidity.

\section{Financial support and sponsorship: Nil.}

Conflict of Interests: There are no conflicts of interest.

\section{REFERENCES}

Ballard C, Corbett A, Chitramohan R, Aarsland D. Management of agitation and aggression associated with Alzheimer's disease: controversies and possible solutions. Curr Opin Psychiatry, 2009; 22:532540 .

Campanelli CM. American Geriatrics Society updated beers criteria for potentially inappropriate medication use in older adults. J Am Geriatr Soc, 2012; 60:616-631.

Colovic MB, Krstic DZ, Lazarevic-Pasti TD, Bondzic AM, Vasic VM. Acetylcholinesterase inhibitors: pharmacology and toxicology. Curr Neuropharmacol, 2013; 11:315-335.

Fick DM, Cooper JW, Wade WE, Waller JL, Maclean JR, Beers $\mathrm{MH}$. Updating the Beers criteria for potentially inappropriate medication 
use in older adults: results of a US consensus panel of experts. Arch Intern Med, 2003; 163:2716-2724

Johnell K, Fastbom J. Concurrent Use of Anticholinergic Drugs and Cholinesterase Inhibitors. Drugs Aging, 2008; 25:871-877.

Katz IR, Sands LP, Bilker W, DiFilippo S, Boyce A, D'Angelo $\mathrm{K}$. Identification of medications that cause cognitive impairment in older people: the case of oxybutynin chloride. J Am Geriatr Soc, 1998; 46:8-13.

Linjakumpu T, Hartikainen S, Klaukka T, Veijola J, Kivelä SL, Isoaho R. Use of medications and polypharmacy are increasing among the elderly. J Clin Epidemiol, 2002; 55:809-817.

Liu HC, Lin SK, Sung SM. Extrapyramidal side-effect due to drug combination of risperidone and donepezil. Psychiatry Clin Neurosci, 2002; 56:479-479.

Lopez O, Becker J, Wisniewski S, Saxton J, Kaufer D, DeKosky S. Cholinesterase inhibitor treatment alters the natural history of Alzheimer's disease. J Neurol Neurosurg Psychiatry, 2002; 72:310-314.

Lyketsos CG, Lee HB. Diagnosis and treatment of depression in Alzheimer's disease. Dement Geriatr Cogn Disord, 2003; 17:55-64.

Magnuson TM, Keller BK, Burke WJ. Extrapyramidal side effects in a patient treated with risperidone plus donepezil. Am J Psychiatry, 1998; 155: 1458-1459.

Narayan SW, Hilmer SN, Horsburgh S, Nishtala PS. Anticholinergic component of the Drug Burden Index and the Anticholinergic Drug Scale as measures of anticholinergic exposure in older people in New Zealand: a population-level study. Drugs Aging, 2013; 30:927-934.

Pasqualetti G, Tognini S, Calsolaro V, Polini A, Monzani F. Potential drug-drug interactions in Alzheimer patients with behavioral symptoms. Clin Interv Aging, 2015; 10:1457-1466.

Paulison B, Léos CL. Potential cardiotoxic reaction involving rivastigmine and beta-blockers: a case report and review of the literature. Cardiovasc Toxicol, 2010; 10:306-310.

Porsteinsson AP, Drye LT, Pollock BG, Devanand D, Frangakis $\mathrm{C}$, Ismail $\mathrm{Z}$, Marano $\mathrm{C}$, Meinert $\mathrm{CL}$, Mintzer JE, Munro CA. Effect of citalopram on agitation in Alzheimer disease: the CitAD randomized clinical trial. JAMA, 2014; 311:682-691.
Preskorn SH. Clinically relevant pharmacology of selective serotonin reuptake inhibitors. Clin Pharmacokinet, 1997; 32:1-21.

Roe CM, Anderson MJ Spivack B. Use of anticholinergic medications by older adults with dementia. J Am Geriatr Soc, 2002; 50:836-842.

Seitz DP, Adunuri N, Gill SS, Gruneir A, Herrmann N, Rochon P. Antidepressants for agitation and psychosis in dementia. Cochrane Database Syst Rev, 2011; 16, 2: CD008191.

Shimizu S, Mizuguchi Y, Sobue A, Fujiwara M, Morimoto T, Ohno Y. Interaction between anti-Alzheimer and antipsychotic drugs in modulating extrapyramidal motor disorders in mice. J Pharmacol Sci, 2015; 127:439-445.

Sink KM, Thomas J, Xu H, Craig B, Kritchevsky S, Sands LP. Dual Use of Bladder Anticholinergics and Cholinesterase Inhibitors: Long-Term Functional and Cognitive Outcomes. J Am Geriatr Soc, 2008; 56:847-853.

Tanaka A, Koga S, Hiramatsu Y. Donepezil-induced adverse side effects of cardiac rhythm: 2 cases report of atrioventricular block and Torsade de Pointes. Intern Med, 2009; 48:1219-1223.

Taragano FE, Lyketsos CG, Mangone CA, Allegri RF, Comesaña-Diaz E. A double-blind, randomized, fixed-dose trial of fluoxetine vs. amitriptyline in the treatment of major depression complicating Alzheimer's disease. Psychosomatics, 1997; 38:246-252.

Tavassoli N, Sommet A, Lapeyre-Mestre M, Bagheri H, Montrastruc JL. Drug Interactions with Cholinesterase Inhibitors. Drug safety, 2007; 30:1063-1071.

\section{How to cite this article:}

Sara Ataei, Maryam Mehrpouya, Amir Nili-Ahmadabadi., Potential drug interactions with cholinesterase inhibitors in Alzheimer patients: A guideline for Neurologists. J App Pharm Sci, 2017; 7 (01): 223-226. 